\title{
Entrepreneurs' gender, age and education shaping motives: push of necessity and pull of opportunity in MENA and Denmark
}

\section{Mahdokht Sedaghat* and Peter Waring Lei}

\author{
International Business Academy, \\ Havneparken 1, 6000, Kolding, Denmark \\ Email: mase@iba.dk \\ Email: pwl@iba.dk \\ *Corresponding author
}

\begin{abstract}
Entrepreneurs are different at engaging in entrepreneurial activities. Some engage in entrepreneurship to avoid unemployment, whereas others pursue a recognised opportunity for profit. This proposition is refined by investigating inequalities among entrepreneurs in terms of age, gender and education. These inequalities are hypothesised to differ from one society to another, here Denmark and Middle East and North Africa (MENA). We hypothesise that gender, age, education and society affect motives. A further refinement is to consider that society moderates the impacts of gender, age and education on motives. A sample of 7,543 entrepreneurs in MENA and 2,973 in Denmark is analysed (2001-2014). Findings show that gender affects motives, in that women in MENA are less often motivated by opportunity than women in Denmark. Age affects motives, in that older entrepreneurs are more frequently opportunity motivated than younger entrepreneurs. Education effects motives, in the way that educated entrepreneurs are more frequently motivated by opportunity. Society effects motives, in that MENA entrepreneurs are less frequently motivated by opportunity. Finally, society moderates the impacts of gender, age and education on motives.
\end{abstract}

Keywords: entrepreneurship; motives; age; gender; education; MENA; Denmark; Global Entrepreneurship Monitor; GEM.

Reference to this paper should be made as follows: Sedaghat, M. and Lei, P.W. (2020) 'Entrepreneurs' gender, age and education shaping motives: push of necessity and pull of opportunity in MENA and Denmark', MENA $J$. Cross-Cultural Management, Vol. 1, No. 1, pp.63-79.

Biographical notes: Mahdokht Sedaghat is Assistant Professor at International Business Academy (IBA), Denmark. She received her Master's degree in Entrepreneurship from University of Tehran (2012). She teaches innovation management, research methods, strategy analysis, HRM and international leadership and management. She participated in several international conferences in international business and entrepreneurship including XXXII RENT Conference (2018). She is the first author and co-author of several academic papers on entrepreneurship and her interests' area is entrepreneurs' motives, networks, innovation, exporting, performance and culture (http://www.iba.dk).

Peter Waring Lei is a Program Manager for MBA, MSc, BA and BSc study programs at International Business Academy (IBA), Denmark. He holds a Master of Law from University of Copenhagen (1997), Master of Philosophy 
from London South Bank University (2018) and Executive MBA from Coventry University (2011). He is the first author and co-author of academic papers. Currently Doctoral Candidate at London South Bank University and his field of doctoral research is International Academic Collaboration between Higher Education Institutions (HEI) (http://www.iba.dk).

\section{Introduction}

Hessels et al. (2008, p.324) argue that "Hardly anybody starts a business in order to achieve innovation, job creation, or economic growth at the national level. Instead, people desire personal profits, or autonomy, amongst others, or are just forced into entrepreneurship because they have no other options". Such motives can be classified as either an opportunity or a necessity, a distinction akin to 'pull' and 'push'. They consider push motives as less prevalent in developed countries. "Necessity entrepreneurs engage in entrepreneurship to avoid unemployment, whereas opportunity entrepreneurs pursue a recognised opportunity for profit" [Anca et al., (2009), p.244]. Necessity entrepreneurs start a business because they have no other source of income. It also means these necessity-based businesses are often less innovative and without growth potential (Nielsen et al., 2017). Necessity entrepreneurship (push motives) arises from family pressure and entrepreneurs' general dissatisfaction with their current situation while opportunity motives (pull) arises from the need for achievement, the desire to be independent and more opportunities for social development (Suchart, 2017). According to Suchart (2017), pull motivation is a requirement for autonomy and social recognition. Necessity entrepreneurs account for an important part of the total set of entrepreneurs in developing countries and are relatively less common in developed countries. In developing countries, entrepreneurship is concerned with starting and accelerating growth, and in providing impulse to the structural transformation of economies; in the advanced economies the concern is mainly with obtaining new sources of productivity growth, which leads to competitiveness (Anca et al., 2009). Hessels et al. (2008) also believe that necessity entrepreneurship is more common in lower-income societies and decrease with the level of economic development.

The GEM Adult Population Survey in 2012 to 2014 measured individuals' involvement in 89 countries.

\footnotetext{
"The survey reported the adults' background details such as gender, age and education; their entrepreneurial competencies such as self-efficacy, opportunity-perception, risk-propensity, and role-modelling by knowing a start-up entrepreneur; and their occupation, and whether they intend to start a business, are trying to start one, or already own/manage a business. Those identified as owning and managing a start-up or operating business were asked additional business-related questions such as motives for being in the business, business age and size, and expectations for growth of the business. The data from the Adult Population Survey have been analysed with a focus on the youth's involvement in entrepreneurship." [Schøtt et al., (2015), p.12]
}

Schøtt et al. (2015) compared the motive for starting a business for the early stage youth entrepreneurs around the world in five regions including Sub-Saharan Africa (SSA), Middle East and North Africa (MENA), South and East Asia (S\&EA), Latin America and the Caribbean (LAC) and European Culture Countries (ECC). The opportunity motive 
prevails over the necessity motive in every region, but to a different extent. The LAC region has the highest prevalence of opportunity motivation $(68 \%)$, S\&EA region has the second highest $(63 \%)$ and ECC including Denmark has the third prevalence of opportunity motivation (61\%). SSA and the MENA region report the highest prevalence of necessity motivated enterprises, $45 \%$ and $42 \%$ respectively (Schøtt et al., 2015).

Nasiri and Hamelin (2018) on a sample of 12,515 nascent entrepreneurs from 17 MENA countries using GEM data from 2009 to 2014 analysed the relationship between nascent entrepreneurial motivation with their education, gender and occupation. They found that individuals who are opportunity-driven entrepreneurs possess a higher level of education in comparison to necessity-driven entrepreneurs. They also found that motive depends on occupation. The pull of opportunity is especially frequent among entrepreneurs coming from full-time employment. Thy found no relationship between gender and motives for becoming an entrepreneur (Nasiri and Hamelin, 2018).

For understanding the real potential of entrepreneurship, it is essential to compare developing societies to more developed societies. In other words, our understanding of life in a region is enhanced when we compare to other regions.

We understand life in MENA better, when we compare MENA to other places around the World, here with Denmark. The difference in culture, the variation among the eco-systems, wealth and high priorities between MENA and other regions in the world requires for comparing entrepreneurship in MENA with entrepreneurship in other regions.

Relatively few studies have been discussing and comparing opportunity and necessity entrepreneurship in different societies. To fill this research gap, we will formulate hypotheses relating to the effects of gender, age, education and society on motives. We then hypothesise that gender, age and education together with society, in combination, shape entrepreneurs' motives.

Therefore, the aim of this research is to examine the effects of entrepreneurs' gender, age, education and society on motives in MENA and Denmark. So, the main research question is: How gender, age, education and society are affecting the motivation of entrepreneurs either being necessity or opportunity driven when comparing MENA and Denmark?

Section 2 of this paper presents the theoretical background and hypotheses which constructs the basis for the research model. Section 3 describes the research design and data. Section 4 presents the results. Section 5 is conclusion. Subsequently, recommendations for future research are discussed along with recommendations for policy makers in the MENA region. Finally, the paper ends by contributions and implications as well as a limitation section.

\section{Theoretical background and hypotheses}

Entrepreneurship is about discovering, evaluating and exploring opportunities regardless of current constraints on resources (Venkataraman, 1997). Another variation of entrepreneurship that derives from Global Entrepreneurship Monitor (GEM) is seeking entrepreneurship due to a paucity of other options to earn a living. It is obvious that different societies with different economies, wealth, culture, history, size and populations have different drivers for entrepreneurship. Hessels et al. (2008) believe that push motives are less prevalent in developed countries. According to World Bank data, middle 
income countries are home to $75 \%$ of the world's population and $62 \%$ of the world's poor. These countries are of great importance as they represent about one-third of global GDP and are major engines of global growth (World Bank, 2019). Entrepreneurs in more developed countries are more likely than entrepreneurs in less developed countries to engage in opportunity-based (pull) entrepreneurship rather than necessity-based (push) entrepreneurship (Sahasranamam and Sud, 2016). Difference in age, education and gender also play an important role in motives for entrepreneurship. Research in a high-income country illustrates that necessity entrepreneurship is largely independent of age, while age has an inverted-U-shape relationship with opportunity entrepreneurship (Bergmann and Sternberg, 2007). In a low-income country, it was seen that the likelihood for opportunity-based and necessity-based entrepreneurship increases with age (Brünjes and Diez, 2013). "Findings in middle-income countries, suggest that as individuals become older, they are less likely to become opportunity entrepreneurs. This could be due to the greater risk associated with opportunity entrepreneurship, coupled with family pressures and job security needs" [Sahasranamam and Sud, (2016), p.34]. Tominc and Rebernik (2004) believe that necessity-based entrepreneurs are dominant in developing countries rather than developed countries. Females are more likely than males to engage in necessity-based entrepreneurship rather than opportunity-based entrepreneurship (Warnecke et al., 2012). However, the difference between these forms of entrepreneurship in less developed countries as compared to developed countries, specifically in terms of age, education and gender, is noticeably absent in the literature available. At the same time, entrepreneurship is often considered the solution to problems such as rising youth unemployment (Chigunta et al., 2005).

In an attempt to explore and fill this research gap, individual level antecedents of opportunity and necessity-based entrepreneurship in MENA and Denmark are investigated.

\subsection{Gender}

Research shows that females are less likely than males to engage in entrepreneurial activities (Phipps and Prieto, 2015; Širec and Močnik, 2012). Orhan and Scott (2001) argue that several attributes closely associated with necessity entrepreneurship were particularly common among female entrepreneurs. These were insufficient family income, dissatisfaction with the salary offered for employment, difficulty finding a job and lack of flexibility in their schedule to accommodate household responsibilities (Orhan and Scott, 2001).

These considerations can be stated as the first hypothesis:

Hypothesis 1 Gender affects motives, in that women are less frequently opportunity motivated than men in MENA and Denmark.

\subsection{Age}

Lévesque and Minniti (2006) examined the effect of age on entrepreneurship based on the opportunity cost of time. They argued that with age, people are less willing to invest time in activities that have a long and uncertain payback period, such as starting a venture. Further, with age, income from wage labour increases as the individual gains experience. This is likely to further increase the opportunity cost associated with starting 
a new venture (Lévesque and Minniti, 2006). Young people are increasingly being encouraged to switch from 'job seekers' to 'job creators' (Langevang and Gough, 2012). However, the majority of them are not well equipped and belong to the group of 'necessity' entrepreneurs instead of 'opportunity' entrepreneurs. 'Necessity' entrepreneurs in general do not have much growth ambition in their businesses. Thus, they have only limited impact on the development of the economy. On the other hand, 'opportunity' entrepreneurs start their businesses from an identified market opportunity. In this way, they are assumed to help build the economy further (Chigunta et al., 2005; Langevang et al., 2012). Bergmann and Sternberg (2007) found that age has an inverse-U-shaped relationship with opportunity-based entrepreneurship. They did not find a significant effect of age on necessity-based entrepreneurship. Wagner (2005) found these relationships to be in reverse. He observed that while there was no effect of age on opportunity-based entrepreneurship, an inverse-U-shaped relationship existed in the case of necessity-based entrepreneurship. Further, opportunity-based entrepreneurs tend to be older than necessity-based entrepreneurs (Block and Sandner, 2009; Wagner, 2005). Suchart's research on entrepreneurs (GEM data 2015) in 13 European countries and ten Asian countries shows that young entrepreneurs seem to become opportunity driven nascent entrepreneurs more often than their older counterparts (Suchart, 2017). Based on a study on entrepreneurs in MENA region, Ismail and colleagues also confirm that "Opportunity-based start-up compared to necessity-based start-up also changes with age. Among the young and also the middle aged, opportunity-based start-up is much more frequent than necessity-based start-up. Among the senior-aged, opportunity-based startup is less dominant. In other words, necessity-based entrepreneurship is more salient among the senior-aged population than among the young and middle-aged" [Ismail et al., (2018), p.539].

These considerations lead to the second hypothesis:

Hypothesis 2 Age affects motives, in that older entrepreneurs are less frequently opportunity motivated than younger entrepreneurs, in MENA and Denmark.

\subsection{Education}

"When looking specifically at the prevalence of the income/wealth motive versus the independence motive within the entrepreneurial population it is obvious that many individual determinants such as experience, personality, education, and financial position play a role when explaining these motives" [Hessels et al., (2008), p.328]. Job satisfaction, previous work experience, entrepreneurial parents, age, and education are the factors which differentiate entrepreneurs from non-entrepreneurs (Gartner, 1989). Gartner believes that education is one of the critical factors in distinguishing entrepreneurs from non-entrepreneurs (Gartner, 1989). Alfalih (2019) emphasises that highly educated entrepreneurs are known to be more able to perceive and exploit successful entrepreneurial opportunities than those with less education. Cho's (1998) study also emphasises the effect of education on motives to create a new venture. Lee et al.'s (2005, p.41) study reveals that "the impact of entrepreneurship education in each country is different because of each country's unique culture in regard to entrepreneurship". "Great diversity exists among entrepreneurs based on their 'growing background' of social, cultural, and educational environments" [Lee et al. (2005), p.29]. Concerning education 
and motives, Autio and Acs (2010) note that higher education levels improve the perception of opportunities. With formal education, individuals are better equipped to learn about markets and technology, and recognise opportunities in the surrounding environment (Shane, 2000). Formal education also allows individuals to develop learning aptitudes and enable skills to exploit those opportunities (Grant, 1996). Hence, individuals who stay within the education system for a longer period are more likely to be opportunity entrepreneurs (Baptista et al., 2014). Poschke (2013) found that necessity entrepreneurs tend to have lower levels of education, run smaller firms, expect their firms to grow less, but are likely to stay in the market for longer periods. Education increases access to social networks and creates a sense of self-efficacy; therefore, any educational advantage for females will translate to upper rates of opportunity-based entrepreneurship (Warnecke et al., 2012). Suchart's (2017) research shows that education is a significant antecedent factor to become an opportunity driven nascent entrepreneur in both Europe and Asia. "Research has shown that the education level of opportunity entrepreneurs is higher than that of necessity entrepreneurs" [Van der Zwan et al., (2016), p.278]. Sarasvathy (2004) argues that individuals who are unhireable due to a lack of education and language skills are pushed to become necessity entrepreneurs. Finally, a study conducted by Nasiri and Hamelin (2018) on a sample of 12,515 nascent entrepreneurs from 17 MENA countries using GEM data from 2009 to 2014 also shows that entrepreneurs' motives depend on their level of education, in that higher education increases the probability of being pulled by opportunity rather than being pushed by necessity.

These considerations lead to the third hypothesis:

Hypothesis 3 Education affects motives, in that educated entrepreneurs are more frequently motivated by opportunity than less educated entrepreneurs, in MENA and Denmark.

\subsection{Society}

Denmark has a unique entrepreneurial environment. According to the 2019 Global Entrepreneurship Index, Denmark's entrepreneurial ecosystem is the fourth best in the world and the first in the EU, scoring 136 countries on 14 pillars of a healthy entrepreneurship ecosystem. Denmark's strongest areas are: opportunity perception, opportunity start-up, technology absorption, human capital, product innovation and risk capital (The Global Entrepreneurship and Development Institute, https://thegedi.org/global-entrepreneurship-and-development-index//).

According to the 2019 Global Entrepreneurship Index, MENA's entrepreneurial ecosystem is as follows: United Arab Emirates scores 25th in the world and the first in the MENA region. Their strongest areas are networking, cultural support, product innovation, high growth and internationalisation. Qatar ranks 28, Saudi Arabia 42, Turkey 44, Kuwait 47, Tunisia 53, Iran 63, Jordan 64, Lebanon 66, Morocco 68, Egypt 81, Algeria 88, Pakistan 108, and Libya 113. Palestine, Syria, and Yemen score very low, therefore they are not on the list (The Global Entrepreneurship and Development Institute, https://thegedi.org/global-entrepreneurship-and-developmentindex//).

Entrepreneurial ecosystem as well as entrepreneurs' motives varies in different societies. Hessels et al. (2008) mention that a study comparing Norway, the UK and 
New Zealand and another study comparing the USA and Israel, found that motives vary between countries. They argue that necessity motives play a major role in developing countries as well as in developed countries, although to a lesser extent.

Shenkar et al. (2014) compared and ranked different countries on their ratio of opportunity to necessity for early-stage entrepreneurs. They found a very high ratio for Denmark (27.4), compared with a very low ratio for China (1.2). They argue that whereas Danish entrepreneurs are likely to start a business as a way to tap opportunities for wealth and personal growth, Chinese entrepreneurs are more likely to take the plunge as a way of overcoming limited employment opportunities (Shenkar et al., 2014). According to Suchart (2017), necessity entrepreneurs are common in developing countries, while opportunity entrepreneurs are prevalent in mostly developed countries.

These considerations lead to the fourth hypothesis:

Hypothesis 4 Society affects motives, in that MENA entrepreneurs are less frequently motivated by opportunity than Danish entrepreneurs.

Figure 1 shows the hypothesised positive effects as solid arrows and the negative effect as a dashed arrow.

Figure 1 Effects on entrepreneurs' motives from gender, age, education and society (see online version for colours)

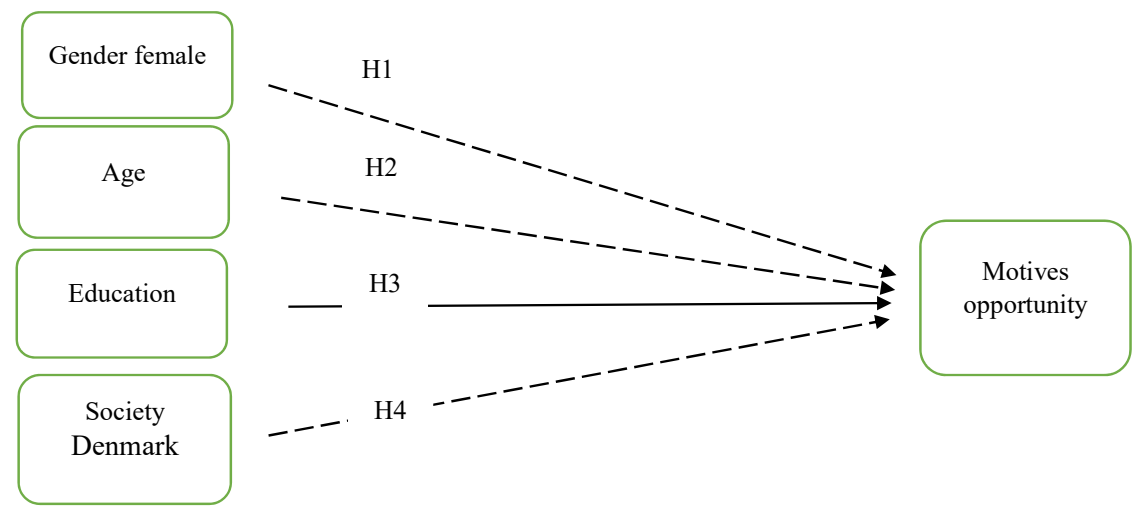

"A higher proportion of men than women engage in entrepreneurship in all developed economies, despite a recent trend increase in female entrepreneurship in some of them" (Parker, 2009). The environment (cultural and political) in which females are located might influence their perceptions, ambitions, personality traits and motives (Santiago Castro and Pisani, 2013). Kalafatoglu and Mendoza (2017) studied women entrepreneurs living and operating businesses in Turkey, Lebanon, Saudi Arabia, Morocco, and Egypt. They examined "how gender and culture affect business creation, how women perceive social capital, and how important their personal networks are for their businesses, especially in the context of patriarchal societies" [Kalafatoglu and Mendoza, (2017), p.332]. They found that "being a woman entrepreneur in a highly patriarchal society limits entrepreneurial activities due to culture and social norms. However, networking appears as the key factor for these women entrepreneurs to 
overcome the barriers that they face, such as access to capital, financial information, resources, and new business opportunities" [Kalafatoglu and Mendoza, (2017), p.332]. Pines et al studied gender differences in entrepreneurship using data from 2007-2008 GEM in 43 countries. They found that in opportunity entrepreneurship the highest gender difference was in high-income countries. In necessity entrepreneurship, the highest gender difference was in low- and middle-income European and Asian countries (Monitor et al., 2012; Pines et al., 2010).

These considerations lead to the fifth hypothesis:

Hypothesis 5 The gender effect on motives depends on society, in that women in MENA are less often motivated by opportunity than women in Denmark.

Age, like gender, shapes motives. Age is an attribute of a person that affects entrepreneur's motives. Based on Becker's (1965) theory of time allocation, for any individual, there exists a threshold age which is critical for the distribution of individual working. After this threshold age is reached, an individual willingness to invest time in starting new activities declines. As we grow older, the opportunity cost of time increases. Thus, the value we attach to time is an increasing function of age. Therefore, as we get older, we become less willing to invest time in activities that have a long and uncertain payback period, such as starting a venture (Lévesque and Minniti, 2006).

Age and society in combination may also affect motives. Motives are more opportunity-based in more developed societies than in less developed societies. Furthermore, in more developed societies, older adults are more opportunity motivated than youngsters.

These considerations lead to the sixth hypothesis:

Hypothesis 6 The age effect on motives depends on society, in that older MENA entrepreneurs are less often motivated by opportunity than their peers in Denmark.

Education shapes motives. In their study on the differences between opportunity and necessity-motivated business owners, Van der Zwan et al. (2016) show that for the Asian sample (in comparison to 25 European countries and the USA), education increase the probability of being an opportunity versus a necessity-motivated business owner.

Education and society may affect motives also in combination. The impact of education on motives is embedded in society. In less developed societies, educated people are a scarce resource, so they may be especially attractive, and in the competition for access to opportunities, their educational certificate may give especially easy access, and both mechanism may boost the motives to seek opportunities in less developed societies.

These considerations lead to the seventh hypothesis:

Hypothesis 7 The education effect on motives depends on society, in that educated MENA entrepreneurs are more often motivated by opportunity than their counterparts in Denmark.

Figure 2 shows the hypothesised positive effects as solid arrows and the negative effect as a dashed arrow. 
Figure 2 Effects on entrepreneurs' motives from the interaction of society with gender, age and education (see online version for colours)

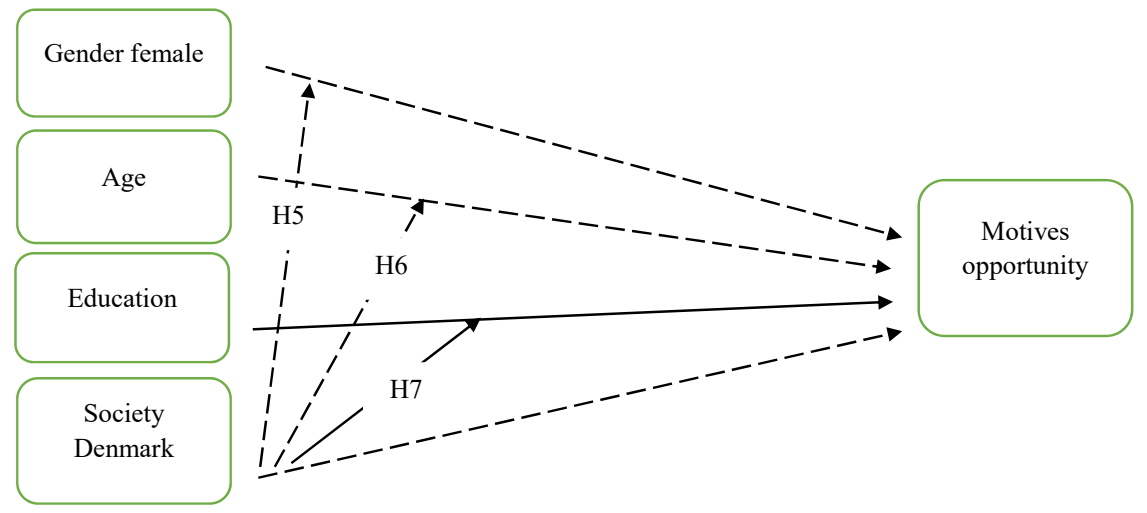

\section{Research design and data}

To investigate entrepreneurs' motives, a sample of entrepreneurs, which is large and fairly representative is needed. Such a sample is available from the GEM surveys (Global Entrepreneurship Research Association, 2020). "GEM is an international research project that aims to identify: a) correlations between a country's entrepreneurship activity and socio-economic growth, b) how entrepreneurial activity varies across countries; and c) which national framework conditions encourage a country's entrepreneurial activities" [Nielsen et al., (2017) pp.52-54]. The GEM survey of individuals can be considered a two-stage sample of the adult population (18-64 years) in the world. In the first stage, countries have been sampled by self-selection; when researchers within some countries formed national teams that joined the GEM consortium. In each such participating country, the second stage was to draw an approximate national probability sample of adults and in interviews identify entrepreneurs.

A sample of 7,543 entrepreneurs in MENA (including United Arab Emirates (358), Algeria (553), Egypt (213), Iran (707), Jordan (293), Kuwait (261), Lebanon (581), Libya (388), Morocco (471), Pakistan (319), Palestine (280), Qatar (1387), Syria (300), Saudi Arabia (260), Tunisia (184), Turkey (463) and Yemen (525)) and 2,973 entrepreneurs in Denmark in the start-up and operating phases is at hand (in the period 2001-2014).

Adults were sampled randomly, and entrepreneurs were identified as those adults who were owner-managers of a start-up or operating enterprise. Therefore, the findings can be generalised with reasonable confidence for all the entrepreneurs in the two surveyed societies.

The entrepreneurs starting or operating a firm reported on their motives, as detailed below, and on other characteristics of themselves and their firms:

- Gender is coded 0 for males and 1 for female entrepreneurs.

- Age is measured in years, ranging from 18 to 64 years.

- Education is measured in years. 
- Motive is measured by asking, are you involved in this start-up to take advantage of a business opportunity or because you have no better choices for work? And is coded 1 if take advantage of business opportunity, 0 if no better choices for work.

- Society is coded 0 for MENA and 1 for Denmark.

The method for testing the hypotheses is logistic regression using SPSS.

\section{Results}

\subsection{Motives by genders and society}

Table 1 shows that men and women are motivated more by opportunity than necessity in MENA. In Denmark, both genders are motivated more by opportunity than necessity. The motivational factors related to gender is very different in these two societies in the way that the difference between men and women is more significant in Denmark than in MENA.

Table 1 Motives by genders and society ( $\mathrm{N}=10,516$ entrepreneurs).

\begin{tabular}{lccccc}
\hline Society & \multicolumn{2}{c}{ MENA } & & \multicolumn{2}{c}{ Denmark } \\
\cline { 1 - 2 } \cline { 5 - 6 } Gender & Men & Women & & Men & Women \\
\hline Opportunity motivated & $59 \%$ & $64 \%$ & & $80 \%$ & $80 \%$ \\
Necessity motivated & $41 \%$ & $36 \%$ & & $20 \%$ & $20 \%$ \\
Total & $100 \%$ & $100 \%$ & & $100 \%$ & $100 \%$ \\
\hline
\end{tabular}

\subsection{Motives by age and society}

Table 2 demonstrates that in MENA, entrepreneur's motives based on opportunity is decreasing by age. On the other hand, necessity-based entrepreneurship is increasing by age. In Denmark, opportunity-based entrepreneurship is decreasing by age and necessity entrepreneurship is increasing by age.

Table 2 Motives by age and society $(\mathrm{N}=10,516$ entrepreneurs $)$

\begin{tabular}{lccccccc}
\hline Society & \multicolumn{3}{c}{ MENA } & & \multicolumn{3}{c}{ Denmark } \\
\cline { 1 - 4 } \cline { 7 - 8 } Age (years) & $18-29$ & $30-49$ & $50-64$ & & $18-29$ & $30-49$ & $50-64$ \\
\hline Opportunity motivated & $61 \%$ & $62 \%$ & $53 \%$ & & $85 \%$ & $82 \%$ & $75 \%$ \\
Necessity motivated & $39 \%$ & $38 \%$ & $47 \%$ & & $15 \%$ & $18 \%$ & $25 \%$ \\
Total & $100 \%$ & $100 \%$ & $100 \%$ & & $100 \%$ & $100 \%$ & $100 \%$ \\
\hline
\end{tabular}

\subsection{Motives by education and society}

Table 3 indicates that entrepreneur's motives by opportunity is increasing by their level of the education in MENA. Their motives by necessity is decreasing by the level of education in MENA. 
In Denmark, entrepreneurs' motives by opportunity are growing by their level of education. Entrepreneurs' motives by necessity are declining by the level of education in Denmark.

The rising and falling educational level in MENA is more significant than in Denmark.

The higher an entrepreneur's education, overall, the more opportunity motivated the entrepreneur is likely to be. In other words, the higher an entrepreneur's education, overall, the less necessity motivated the entrepreneur is likely to be.

Table 3 Motives by education and society ( $\mathrm{N}=10,516$ entrepreneurs)

\begin{tabular}{lcccc}
\hline Society & \multicolumn{4}{c}{ MENA } \\
\hline Education & $\begin{array}{c}\text { Less than } \\
\text { secondary degree }\end{array}$ & $\begin{array}{c}\text { Secondary } \\
\text { degree }\end{array}$ & $\begin{array}{c}\text { Postsecondary } \\
\text { education }\end{array}$ & $\begin{array}{c}\text { Graduate } \\
\text { education }\end{array}$ \\
\hline Opportunity motivated & $49 \%$ & $60 \%$ & $70 \%$ & $79 \%$ \\
Necessity motivated & $51 \%$ & $40 \%$ & $30 \%$ & $21 \%$ \\
Total & $100 \%$ & $100 \%$ & $100 \%$ & $100 \%$ \\
\hline Society & \multicolumn{4}{c}{ Denmark } \\
\hline \multirow{2}{*}{ Education } & Less than & Secondary & Postsecondary & Graduate \\
& secondary degree & degree & education & education \\
\hline Opportunity motivated & $75 \%$ & $77 \%$ & $80 \%$ & $84 \%$ \\
Necessity motivated & $25 \%$ & $23 \%$ & $20 \%$ & $16 \%$ \\
Total & $100 \%$ & $100 \%$ & $100 \%$ & $100 \%$ \\
\hline
\end{tabular}

\subsection{Motives by society}

Table 4 shows that entrepreneurs in MENA are more opportunity motivated rather than necessity motivated. In Denmark, entrepreneurs are more motivated by opportunity rather than necessity. There is considerable variation between motives in terms of opportunity and necessity in these two societies.

Table 4 Motives by society ( $\mathrm{N}=10,516$ entrepreneurs)

\begin{tabular}{lcc}
\hline Society & MENA & Denmark \\
\hline Opportunity motivated & $60 \%$ & $80 \%$ \\
Necessity motivated & $40 \%$ & $20 \%$ \\
Total & $100 \%$ & $100 \%$ \\
\hline
\end{tabular}

\subsection{Logistic regression results}

This section tests the hypotheses statistically, first about effects of gender, age, education and society on motives, secondly whether gender, age and education effects on motives depend on society. Table 5 represents the results of logistic regression modelling.

The result of the test indicates that a statistically significant relationship exists between gender and motives, age and motives, education and motives as well as between society and motives in MENA and Denmark, with a p-value of 0.009, 0.001, 0.0001 and 0.0001 , respectively. Based on these results, the first four hypotheses are accepted. 
Table 5 Entrepreneurs' motives affected by gender, age, education and society

\begin{tabular}{lcc}
\hline & Coefficient & Probability-value \\
\hline Gender female & 0.13 & 0.009 \\
Age & -0.006 & 0.001 \\
Education & 0.08 & $<0.0001$ \\
Society Denmark & 0.75 & $<0.0001$ \\
\hline
\end{tabular}

Note: Based on two societies with 10,516 entrepreneurs.

In other words, women in MENA are less often motivated by opportunity than women in Denmark (H1). Older entrepreneurs are more frequently opportunity motivated than younger entrepreneurs (H2).

Educated entrepreneurs are more frequently motivated by opportunity than less educated ones (H3).

MENA entrepreneurs are less frequently motivated by opportunity than Danish entrepreneurs (H4).

\subsection{Logistic regression results (with interaction effects)}

We had also hypothesised that the gender effect on motives depends on society; the age effect on motives depends on society. Finally, education effect on motives depends on society as well.

The results of the logistic regression analysis with interaction effects are shown in Table 6.

Table 6 Entrepreneurs' motives affected by gender, age, education, society and a combination of society with gender, age and education

\begin{tabular}{lcc}
\hline & Coefficient & Probability-value \\
\hline Gender female & 0.21 & 0.0003 \\
Age & -0.002 & 0.33 \\
Education & 0.09 & $<0.0001$ \\
Society Denmark & 1.93 & $<0.0001$ \\
Society*Gender & -0.286 & 0.013 \\
Society*Age & -0.017 & 0.0004 \\
Society*Education & -0.028 & 0.050 \\
\hline
\end{tabular}

Note: Based on two societies with 10,516 entrepreneurs.

As illustrated in Table 6, the interaction effect of society and gender on motives is negative and significant. The gender effect on motives depends on society, in that women in MENA are less often motivated by opportunity than women in Denmark (H5).

The interaction effect of society and age on motives is negative and significant. The age effect on motives depends on society, in that older MENA entrepreneurs are less often motivated by opportunity than their peers in Denmark (H6).

The interaction effect of society and education on motives is negative and significant. The education effect on motives depends on society, in that educated MENA entrepreneurs are less often motivated by opportunity than their counterparts in Denmark (H7). 


\section{Conclusions}

This study outlines the characteristics and determinants of MENA and Danish entrepreneurs and illustrates the distinctive attributes of these entrepreneurs. The aim of the paper is to shed some additional light onto this area: Entrepreneurs' motives shaped by gender, age, education and societal effects: MENA and Denmark. The overall sample size of data from MENA was 7,543 and Denmark 2,973. The issue has discussed how entrepreneurial motives unfold in society, specifically how entrepreneurs' motives differ by age, gender and education. Seven hypotheses have been specified.

Gender was hypothesised as being negatively affected by motives; in that women are less frequently opportunity motivated than men in MENA and Denmark. Results show that gender affects motives; meaning that women in MENA are less often motivated by opportunity than women in Denmark. This positive effect of gender supports Hypothesis 1. Surprisingly our results are in contrast with what Nasiri and Hamelin's (2018) found on their study of a sample of 12,515 nascent entrepreneurs from 17 MENA countries. They found that gender has no discernible effect on the motives for becoming entrepreneur (Nasiri and Hamelin, 2018).

Age was hypothesised as being negatively affected by motives; in that older entrepreneurs are less frequently opportunity motivated than younger entrepreneurs in MENA and Denmark. Results show that age affects motives negatively; meaning that older entrepreneurs are more frequently opportunity motivated than younger entrepreneurs. This negative effect of age supports Hypothesis 2.

Education was hypothesised as being positively affected by motives; in that educated entrepreneurs are more frequently motivated by opportunity than less educated entrepreneurs in MENA and Denmark. Education effects motives (the effect is positive and significant). Therefore, educated entrepreneurs are more frequently motivated by opportunity than less educated entrepreneurs in MENA and Denmark. This positive effect of education supports Hypothesis 3. Our findings are aligned with earlier studies that find higher educated individuals have less difficulty in finding employment, thus, they have a higher likelihood of becoming opportunity-driven entrepreneurs (Block and Wagner, 2007; Sarasvathy, 2004).

Society was hypothesised as being negatively affected by motives; in that MENA entrepreneurs are less frequently motivated by opportunity than Danish entrepreneurs. Society affects motives (the effect is positive and significant). Therefore, MENA entrepreneurs are less frequently motivated by opportunity than Danish entrepreneurs. This positive effect corroborates Hypothesis 4.

We also hypothesised that the gender effect on motives depends on society; in that women in MENA are especially seldom motivated by opportunity. Interaction effect of society and gender on motives is negative and significant; meaning that women in MENA are less often motivated by opportunity than women in Denmark. This negative effect supports Hypothesis 5.

We then hypothesised that the age effect on motives depends on society; in that older MENA entrepreneurs are especially rarely motivated by opportunity. The interaction effect of society and age on motives is negative and significant; meaning that older MENA entrepreneurs are less often motivated by opportunity than their peers in Denmark. This negative effect supports Hypothesis 6.

Finally, we hypothesised that the effect of education on motives depends on society; in that educated MENA entrepreneurs are especially often motivated by opportunity. The 
interaction effect of society and education on motives is negative and significant. The education effect on motives depends on society, in that educated MENA entrepreneurs are less often motivated by opportunity than their counterparts in Denmark (H7).

This result is consistent with the existing entrepreneurship literature. For instance, Suchart (2017) studied a sample of nascent entrepreneurs from 13 countries of Europe including Sweden and Norway, and 10 countries of Asia including Iran. He found that education has a positive effect on the likelihood of being an opportunity driven nascent entrepreneur in both Europe and Asia (Suchart, 2017).

\section{Recommendations for future research}

Entrepreneurs' motives differ by age, gender, education as well as age range, education range and between genders in MENA and Denmark. Other factors like culture affects their motives as well. The two societies differ in culture; traditional culture prevails in MENA, whereas Denmark has a more modern culture. It could also be challenging to consider another environmental national variable like trust.

Another study could investigate how other factors - like environmental legislation, e.g., tax, intellectual property and labour laws, which might be tougher in MENA region - might affect entrepreneurs' motives. The unemployment rate as well as unemployment duration (Nikiforou et al., 2019) are other factors, which are different in MENA and Denmark that leads to opportunity, or necessity-based entrepreneurship. The unemployment rates for the non-oil-producing economies of the MENA-region are among the highest in the world.

To improve the understanding of entrepreneurship and contribute to developing a broader vision that includes both economic and non-economic aspects, we recommend re-examining the motivation variable from the GEM and other entrepreneurship studies. This variable should include other possible categories that consider social aspects and how context variables determine possibilities for entrepreneurship in the specific context of the MENA region. Finally, it is suggested to GEM to consider three types of entrepreneurial motivation: necessity, opportunity and transition (Puente et al., 2019).

\section{Recommendations for policy makers in the MENA region}

"The MENA region must create the institutional infrastructure appropriate for the development of entrepreneurship, especially financial legislation. MENA must promote the creation of parallel educational programs to cultivate entrepreneurial skills at all levels of a given economy, including the non-governmental sector" [Eid, (2011), p.1]. MENA should support business growth with technical assistance and education. They should "incorporate various 'appropriate' versions of entrepreneurship education and capacity building at all levels, ranging from executive education and awareness raising, to the education of young women in schools, to microfinance for those with limited ted education and means in rural and urban areas" [Eid, (2011), p.12].

The MENA region requires a reduction in poverty and unemployment in order to mitigate necessity-based entrepreneurship and increase in human capital, better access to credit, and more transparent business regulations to promote opportunity-based entrepreneurship. 


\section{Contributions and implications}

The design carries significant value in the way that the representativeness in the sampling together with a large sample size enable the findings to be generalised to entrepreneurs in MENA and Denmark.

Theoretically, one value is to distinguish between entrepreneurs' gender, age, education and society and to elaborate and test propositions about the different effects of these variables upon motives.

Another theoretical value of the study is to elaborate and test propositions about how the gender effect on motives depends on society as well as age effects and education effects.

More generally, our study of motives, as influenced by gender, age, education and society, contributes to an understanding of entrepreneurial endeavours as performed by individual actors, the entrepreneurs, in a micro-level context, and in a macro-level context, their governments.

\section{Research limitation}

It was only possible to take into account a limited number of motives currently measured as part of the GEM project.

Another limitation of this study was lack of qualitative information to enable the author to triangulate with quantitative data, to corroborate research findings.

\section{Acknowledgements}

The Global Entrepreneurship Monitor provided the data. The authors would like to extend special thanks to Thomas Schøtt who did the analysis and helped editing.

Special thanks go to Keld Hvam who helped editing.

\section{References}

Alfalih, A.A. (2019) 'Investigating critical resource determinants of start-ups: an empirical study of the MENA region', Cogent Economics \& Finance, Vol. 7, No. 1, pp.1-19.

Anca, B., Viorel, C. and Elena, D. (2009) The Role of The Necessity And The Opportunity Entrepreneurship In Economc Development, Analele Universității Din Oradea, 241.

Autio, E. and Acs, Z.J. (2010) 'Intellectual property protection and the formation of entrepreneurial growth aspirations', Strategic Entrepreneurship Journal, Vol. 4, No. 4, pp.234-251.

Baptista, R., Karaöz, M. and Mendonça J. (2014) 'The impact of human capital on the early success of necessity versus opportunity-based entrepreneurs', Small Business Economics, Vol. 24, No. 42, pp.831-847.

Becker, G. (1965) 'A theory of the allocation of time', Economic Journal, Vol. 75, No. 299, pp.493-517.

Bergmann, H. and Sternberg, R. (2007) 'The changing face of entrepreneurship in Germany', Small Business Economics, Vol. 28, Nos. 2-3, pp.205-221. 
Block, J. and Sandner, P. (2009) 'Necessity and opportunity entrepreneurs and their duration in self-employment: evidence from German micro data', Journal of Industry, Competition and Trade, Vol. 9, No. 2, pp.117-137.

Block, J.H. and Wagner, M. (2007) 'Opportunity recognition and exploitation by necessity and opportunity entrepreneurs: empirical evidence from earnings equations', Academy of Management Proceedings, Vol. 2007, No. 1, pp.1-6.

Brünjes, J. and Diez, J.R. (2013) ' 'Recession push' and 'prosperity pull' entrepreneurship in a rural developing context', Entrepreneurship \& Regional Development, Vol. 25, Nos. 3-4, pp.251-271.

Chigunta, F., Schnurr, J., James-Wilson, D. and Torres, V. (2005) Being 'Real' About Youth Entrepreneurship in Eastern and Southern Africa, (SEED) Working Paper No. 72, International Labor Organization, Geneva.

Cho, B. (1998) 'Study of the effective entrepreneurship education method and its process', Business Education Research, Vol. 2, No. 1, pp.27-47.

Eid, F. (2011) 'Entrepreneurial finance for job creation in the Arab world: strategy elements urgent as ever', Strategic Change, Vol. 20, Nos. 1-2, pp.1-16.

Gartner, W.B. (1989) 'Who is an entrepreneur? is the wrong question', American Journal of Small Business, Vol. 12, No. 4, pp.11-22.

Global Entrepreneurship Research Association (2020) Global Entrepreneurship Monitor [online] http://www.gemconsortium.org (accessed 16 February 2020).

Grant, R. (1996) 'Toward a knowledge-based theory of the firm', Strategic Management Journal, Vol. 17, No. S2, pp.109-122.

Hessels, J., Van Gelderen, M. and Thurik, R. (2008) 'Entrepreneurial aspirations, motivations, and their drivers', Small Business Economics, Vol. 31, No. 3, pp.323-339.

Ismail, A., Tolba, A., Ghalwash, S., Alkhatib, A., Karadeniz, E.E., Ouazzani, K.E., Boutaleb, F., Belkacem, L. and Schøtt, T. (2018) 'Inclusion in entrepreneurship, especially of women, youth and unemployed: status and an agenda for research in Middle East and North Africa', World Review of Entrepreneurship, Management and Sustainable Development, Vol. 14, No. 4, pp.528-547.

Kalafatoglu, T. and Mendoza, X. (2017) 'The impact of gender and culture on networking and venture creation: an exploratory study in Turkey and MENA region', Cross Cultural \& Strategic Management, Vol. 24, No. 2, pp.332-349.

Langevang, T. and Gough, K. (2012) 'Diverging pathways: young female employment and entrepreneurship in Sub-Saharan Africa', The Geographical Journal, Vol. 178, No. 3, pp.242-252.

Langevang, T., Namatovu, R. and Dawa, S. (2012) 'Beyond necessity and opportunity entrepreneurship: motivations and aspirations of young entrepreneurs in Uganda', International Development Planning Review, Vol. 34, No. 4, pp.439-459.

Lee, S.M., Chang, D. and Lim, S.B. (2005) 'Impact of entrepreneurship education: a comparative study of the US and Korea', International Entrepreneurship and Management Journal, Vol. 1, No. 1, pp.27-43.

Lévesque, M. and Minniti, M. (2006) 'The effect of aging on entrepreneurial behaviour', Journal of Business Venturing, Vol. 21, No. 2, pp.177-194.

Monitor, G.E., Keller, D., Singer, S. and Harrington, M. (2012) Journal Global Entrepreneurship Research Association, London Business School.

Nasiri, N. and Hamelin N. (2018) 'Entrepreneurship driven by opportunity and necessity: effects of educations, gender and occupation in MENA', Asian Journal of Business Research, Vol. 8, No. 2, pp.57-71.

Nielsen, S.L., Klyver, K., Evald, M.R. and Bager, T. (2017) Entrepreneurship in Theory and Practice-Paradoxes in Play, 2nd ed., Edward Elgar Publishing Limited, UK.

Nikiforou, A.I., Dencker, J.C. and Gruber, M. (2019) 'Necessity entrepreneurship and industry choice in new firm creation', Strategic Management Journal, Vol. 40, No. 13, pp.2165-2190. 
Orhan, M. and Scott, D. (2001) 'Why women enter into entrepreneurship?, An explanatory model', Women in Management Review, Vol. 16, No. 5, pp.232-243.

Parker, S.C. (2009) The Economics of Entrepreneurship, 1st ed., Cambridge University Press, Cambridge, MA.

Phipps, S.T.A. and Prieto, L.C. (2015) 'Women versus men in entrepreneurship: a comparison of the sexes on creativity, political skill, and entrepreneurial intentions', Academy of Entrepreneurship Journal, Vol. 21, No. 1, pp.32-43.

Pines, A.M., Lerner, M. and Schwartz, D. (2010) 'Gender differences in entrepreneurship', Equality, Diversity and Inclusion: An International Journal, Vol. 29, No. 2, pp.186-198.

Pistrui, D., Huang, W., Oksoy, D., Jing, Z. and Welsch, H. (2001) 'Entrepreneurship in China: characteristics, attributes, and family forces shaping the emerging private sector', Family Business Review, Vol. 14, No. 2, pp.141-152.

Poschke, M. (2013) 'Entrepreneurs out of necessity: a snapshot', Applied Economics Letters, Vol. 20, No. 7, pp.658-663.

Puente, R., Espitia, C.G.G. and Cervilla, M.A. (2019) 'Necessity entrepreneurship in Latin America: it's not that simple', Entrepreneurship \& Regional Development, Vol. 31, Nos. 9-10, pp.953-983.

Sahasranamam, S. and Sud, M. (2016) 'Opportunity and necessity entrepreneurship: a comparative study of India and China', Academy of Entrepreneurship Journal, Vol. 22, No. 1, pp.21-40.

Santiago Castro, M. and Pisani, M. (2013) An Initial Review of the Characteristics and Determinants of Female Entrepreneurs in Puerto Rico, AD-minister, p.23.

Sarasvathy, S. (2004) 'Constructing corridors to economic primitives', in Butler, J.E. (Ed.): Opportunity Identification and Entrepreneurial Behaviour, pp.291-312.

Schøtt, T., Kew, P. and Cheraghi, M. (2015) 'Future potential', A GEM Perspective on Youth Entrepreneurship.

Shane, S. (2000) 'Prior knowledge and the discovery of entrepreneurial opportunities', Organization Science, Vol. 11, No. 4, pp.448-469.

Shenkar, O., Luo, Y. and Chi, T. (2014) International Business, 3rd ed., Routledge, New York.

Širec, K. and Močnik, D. (2012) 'Gender specifics in entrepreneurs' personal characteristics', Journal for East European Management Studies, Vol. 17, No. 1, pp.11-39.

Suchart, T. (2017) 'Factors influencing opportunity driven nascent entrepreneurs in Europe and Asia', European Research Studies, Vol. 20, No. 3A, pp.774-782.

The Global Entrepreneurship and Development Institute [online] https://thegedi.org/globalentrepreneurship-and-development-index// (accessed 29 February 2020).

Tominc, P. and Rebernik, M. (2004) 'The scarcity of female entrepreneurship', Drustvena Istrazivanja, Vol. 13, No. 4, pp.779-802.

Van der Zwan, P., Thurik, R., Verheul, I. and Hessels, J. (2016) 'Factors influencing the entrepreneurial engagement of opportunity and necessity entrepreneurs', Eurasian Business Review, Vol. 6, No. 3, pp.273-295.

Venkataraman, S. (1997) 'The distinctive domain of entrepreneurship research', in Katz, J. (Ed.): Advances in Entrepreneurship, Firm Emergence and Growth, pp.119-138, JAI Press.

Wagner, J. (2005) Nascent Necessity and Opportunity Entrepreneurs in Germany: Evidence from the Regional Entrepreneurship Monitor (REM), Discussion Paper No. 1608, Retrieved from the Institute for the Study of Labor (IZA) [online] http://ftp.iza.org/dp1608.pdf (accessed 16 February 2020).

Warnecke, T., Hernandez, L., and Nicholas, N. (2012) Female Entrepreneurship in China: Opportunity- or Necessity-Based?, Student-Faculty Collaborative Research, Paper 23.

World Bank (2019) [online] http://www.worldbank.org/en/country/mic/overview/ (accessed 16 February 2020). 